\title{
Experimental Investigation of Standard Handling and Storage Duration on Fuel Properties, Appearance, Burning Process and Emissions of Biodegradable Alternative Fuel
}

\author{
Norazwan Azman ${ }^{1, \text { a }}$, Bukhari Manshoor ${ }^{1, \mathrm{~b}}$,Dahrum Samsudin ${ }^{1, \mathrm{c}}$, \\ Amir Khalid ${ }^{1, d}$ \\ ${ }^{1}$ Combustion Research Group (ARG), Centre for Energy and Industrial Environment Studies \\ (CEIES), Universiti Tun Hussein Onn Malaysia, Parit Raja, Batu Pahat, 86400 Johor, Malaysia. \\ aazwanazman1989@gmail.com, bbukhari@uthm.edu.my, \\ 'dahrumsamsudin@yahoo.comªmirk@uthm.edu.my
}

Keywords: Storage Duration, Biodiesel, Alternative Fuel, Fuel Properties

\begin{abstract}
Concern shortage and limited of petroleum, bio-fuels or also known as alternative fuel offer an advantage in order to sustain in long terms and economical. This renewable source is a good offer as an improvement attempt of automobile fuel and burner combustion. The main issue in using biodegradable alternative fuel such as vegetable oil-based fuels is oxidation stability, stoichiometric point, bio-fuel composition, antioxidants on the degradation and much oxygen with comparing to diesel gas oil. Thus, this study investigated the effects of different kind of biodegradable alternative fuel tested at variant in storage ambient condition under different storage duration. These tests were performed on the biodegradable alternative fuel such crude palm oil (CPO), and waste cooking oil (WCO) with different of ambient temperature and variant of blending ratio. The biodegradable fuel samples were stored in clinical compartment, at different temperatures and were monitored at regular interval over a period of 60 days. Blending of biodiesel was varied from $5 \mathrm{vol} \% \sim 15 \mathrm{vol} \%$ and storage temperature from $5^{\circ} \mathrm{C} \sim 33^{\circ} \mathrm{C}$. The effects of ambient temperature and storage duration on properties of biodegradable fuel such as density, kinematics viscosity, acid value, water content and flash point of biodiesel were discussed in detail. Analysis of this study showed that the different storage duration gave a significant effect toward the changes of water content; acid value and viscosity. As a conclusion, a long period of storage would decrease the quality of biodiesel no matter what kind of condition and environment is exposed to.
\end{abstract}

\section{Introduction}

In this fresh era is now the world's energy requirement has increased.This has been tested over the final two decades; the troubles linked with these fuels arise.Foremost, the cost of fossil fuels goes up too quickly and indirectly provides an extra burden to the saving of the importing nations.Second, the combustion of fossil fuels has contributed to an increase in global CO2 levels, which commit the world to global warming [1]. The standard storage and handling procedures used for biodiesel is the main issue for biodiesel fuel specifications [2-5]. Some researchers have shown that biodiesel storage period and temperature related to the purpose of biodiesel properties and quality of biodiesel. Reported that the fatty acid methyl ester molecules are broken down during degradation and chain fatty acids increase the biodiesel.Therefore, the more the degradation, the higher will be its acidity [6]. In addition, the properties test considered to investigate are included density, kinematic viscosity, water content, acid value and flash points test with increasing storage time.

In this work, the percentage of biodiesel sample variance will save on storage conditions at indoor condition and outdoor condition. Observation of samples tested each week for a period of 1680 hours. It is proposed that this study will offer knowledge on the best method of storage features. 


\section{Experimental Setup}

In this field, the raw materials utilized as the principal stuff is crude palm oil (CPO) and waste cooking oil (WCO).Blending process was taken to ascertain that the mixture of diesel and biodiesel is well mixed uniformly.Formal view of blending process is depicted in figure 1. During blending process, the laboratory scale, blending machine was operated at $60^{\circ} \mathrm{C}$ and the mixture was stirred at $70^{\circ} \mathrm{C}$ for 1 hour. The rotating blade speed was adjusted to keep the same speed at 270 RPM.

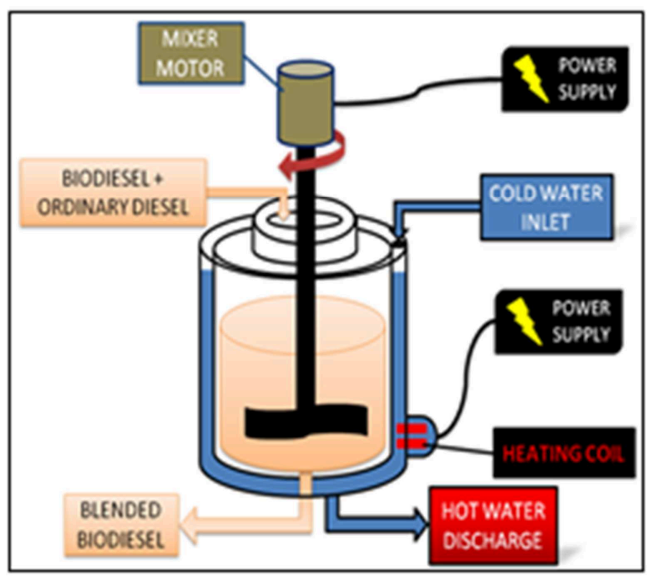

(a) Schematic of blending process

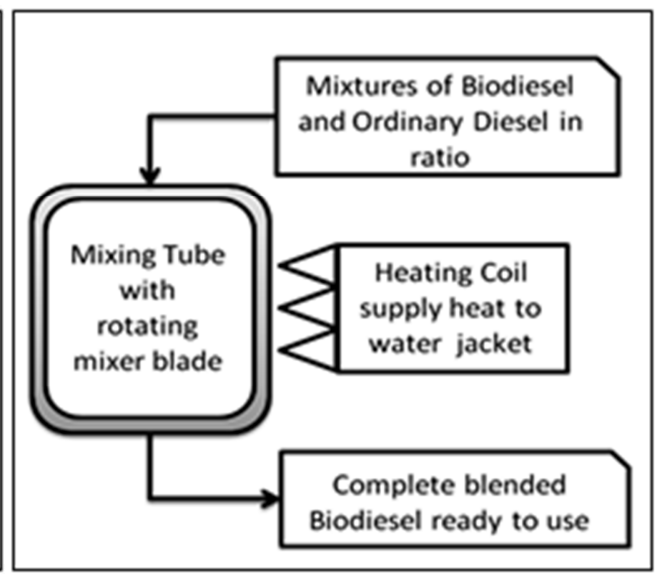

(b) Diagram blending process

Fig.1. Illustrating the blending process

The properties test considered to be investigated are included density, kinematic viscosity, water content, acid value and flash points test [7-9].These properties test are established along the European Standard for Biodiesel (EN 14214) and American Society of Testing Materials (ASTM D6751). The density properties were measured by Metter Toledo Diamond Scale modelled JB703$\mathrm{C} / \mathrm{AF}$. In this inquiry, the kinematic viscosity of sample blend was measured by Viscolite 700 model VL700-T15.Kinematic viscosity is referring to the time consumed from a volume of sample (liquid form) to flow under gravity through a calibrated glass capillary Viscometer. The water content and acid value in the biodiesel sample were measured by Volumetric KF Titrator model v20 and titration process. The condition of acid value is shown as the amount (mg) of potassium hydroxide required to neutralize one gram of the biodiesel. During acid value measurement, the sample is titrated with alcoholic $\mathrm{KOH}$ using phenolphthalein as indicator. The flash point measured by Pensky-Martens PMA 4. The particulars of the tested fuels are detailed in Table 1

Table 1; Properties of blending biodiesel ratio at 1680 hours storage time

\begin{tabular}{|l|l|l|l|l|l|l|}
\hline \multirow{2}{*}{ Sample } & \multicolumn{2}{|c|}{ Acid Value } & \multicolumn{2}{c|}{ Density } & \multicolumn{2}{c|}{ Flash Point } \\
\cline { 2 - 7 } & \multicolumn{1}{|c|}{ Indoor } & \multicolumn{1}{c|}{ Outdoor } & \multicolumn{1}{c|}{ Indoor } & \multicolumn{1}{c|}{ Outdoor } & \multicolumn{1}{c|}{ Indoor } & \multicolumn{1}{c|}{ Outdoor } \\
\hline CPO5 & 0.257 & 0.452 & 0.849 & 0.852 & 84.5 & 82.5 \\
\hline CPO10 & 0.315 & 0.483 & 0.848 & 0.85 & 84.5 & 83.5 \\
\hline CPO15 & 0.368 & 0.562 & 0.848 & 0.857 & 85.5 & 84 \\
\hline WCO5 & 0.26 & 0.28 & 0.846 & 0.852 & 77.4 & 77 \\
\hline WCO10 & 0.4 & 0.42 & 0.855 & 0.854 & 88 & 87.7 \\
\hline WCO15 & 0.64 & 0.68 & 0.857 & 0.856 & 103.5 & 103.5 \\
\hline
\end{tabular}

\section{Results and Discussion}

Physical attributes can be set or measured without changing the makeup of matter and explain it.In this work, it is important to look into the physical attributes of the sample CPO and WCO to make 
fuel for diesel locomotives. Among the properties that can be investigated are the acid value, viscosity, flash point, water content, and density. The experimental investigation of alternative fuel, $\mathrm{CPO}$ and WCO oil ratio on the properties of blends have been investigated on the basis of diesel fuel standard (STD Fuel)for CPO of 5 (CPO5), 10 (CPO10), 15 (CPO15), WCO of 5 (WCO5), 10 (WCO10) and 15 (WCO15) for variant storage condition of indoor temperature and outdoor temperature.

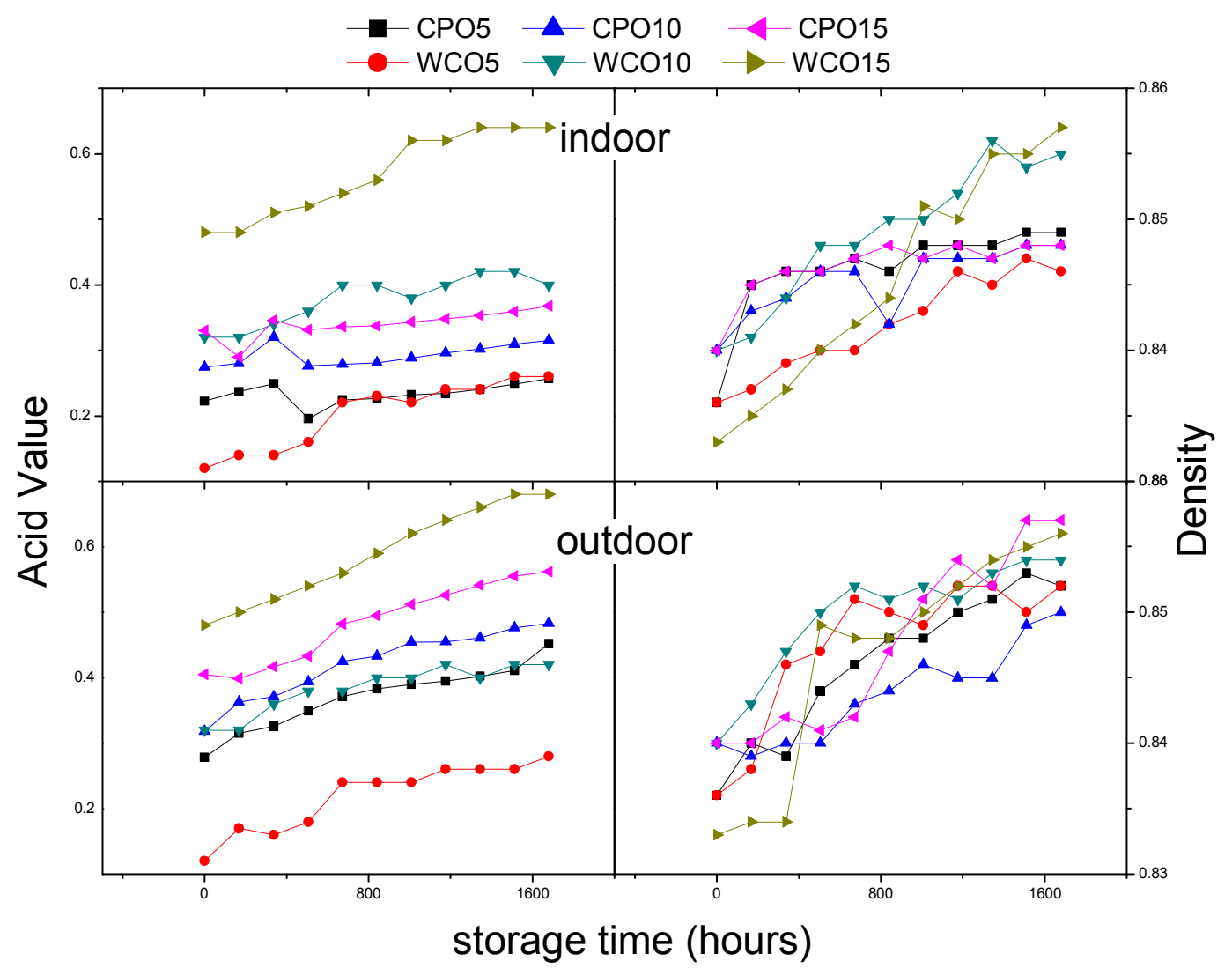

Figure 2 : Effects of storage duration on acid value and density

Figure 2 clearly indicates that increasing the duration of storage at indoor condition to encourage more alternative fuel acid value and density, especially the higher alternative fuel blending ratio WCO15. For acid value properties testing the increasing of blending ratio, thus predominantly influences the increasing of storage duration except the outdoor condition testing it is shownscattered of blending ratio it influences the increasing of fuel storage duration, 


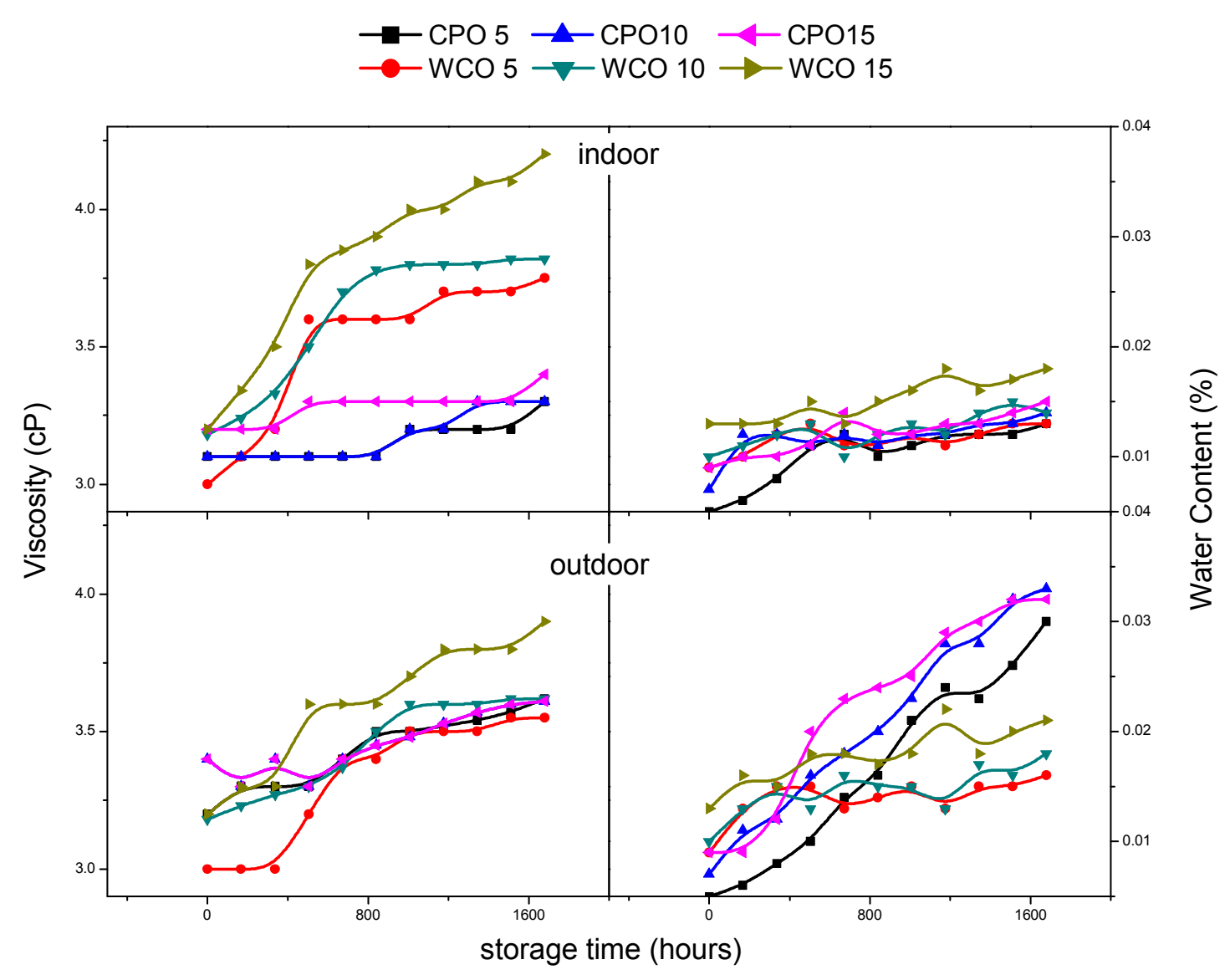

Figure 3 : Effects of storage duration on viscosity and water content

Figure 3 clearly shows that increasing the duration of storage at indoor condition to encourage more alternative fuel viscosity and water content, especially the higher alternative fuel blending ratio WCO15. For viscosity properties testing the increasing of blending ratio thus predominantly influences the increasing of storage duration except the outdoor condition testing it shown scattered of blending ratio it influences the increasing of fuel storage duration,

\section{Conclusion}

In this research, the CPO and WCO fuel with different blending ratio (CPO5, CPO10, CPO15, WCO5, WCO10 and WCO15) which storage at indoor condition and outdoor condition.The summary as follows:

1. This research proves that low changes in the physical attributes of alternative fuel samples when stored at indoor condition and outdoor condition.

2. Indoor storage conditions which are less susceptible to delayed break light chain fatty acids.

3. Alternative fuel storage at indoor condition is suitable and more advantageous because the impact on the physical properties is minimal and beneficial to slow down the degradation of biodiesel and storage.

\section{Acknowledgements}

The authors also would like to thank the UniversitiTun Hussein Onn Malaysia and Ministry of Education, Malaysia for supporting this research under COE-MTUN Grant Scheme VOT.C010. 


\section{References}

[1] Deepak, "Emission Perform. Straight Veg. oils (JatrophaNeem) Fuelled Direct Inject". Compression Ignition Engine, 2012.

[2] Yo-Ping $\mathrm{Wu}, \mathrm{Ya}$ Fen Lin and Jhen-Yu Ye (2011), "The Effect Storage Condition on Biodiesel", Department of Chemical and materialsEngineering, National Ilan University Taiwan, R.O.C.

[3] J.A. Kinast (2003), "Production of Biodiesels from Multiple Feedstocks and Properties of Biodiesel and Biodiesel / Diesel Blends", GasTechnology Institute Des Plaines, Illinois, Final Report 1 in a series of 6.

[4] Amir Khalid, Norazwan Azman, Hanis Zakaria, B. Manshoor, Izzuddin Zaman, Azwan Sapit, Mutalib Leman, "Effects of storage duration on biodiesel properties derived from waste cooking oil”, Applied Mechanics and Materials, Volume 554, 2014, Pages 494-499, DOI: 10.4028/www.scientific.net/AMM.554.494.

[5] Amir Khalid, N.Tamaldin, M. Jaat, M. F. M. Ali, B. Manshoor, Izzuddin Zaman, "Impacts of biodiesel storage duration on fuel properties and emissions", Procedia Engineering, volume 68, 2013, Pages 225 - 230, Elsevier, 2013, DOI: 10.1016/j.proeng.2013.12.172.

[6] Jinllin Xue, Tony E. Grift, Alan C. Hansen, "Effect of biodiesel on engine performances and emission”, Department of Agricultural andBiological Engineering, University of Illinois at Urbana-Champingn, Urbana, USA. (2011).

[7] Amir Khalid, M.D. Anuar, YusriIshak, B. Manshoor, AzwanSapit, Mutalib Leman, Izzuddin Zaman, "Emissions characteristics of small diesel engine fuelled by waste cooking oil", MATEC Web of Conferences, Volume 13, 2014, Article number 06006, DOI: 10.1051/matecconf/20141306006.

[8] Meher, L. C., VidyaSagar, D., \&Naik, S. N. (2006). Technical Aspects Of Biodiesel Production By Transesterification-A Review. Renewable And Sustainable Energy Reviews, 10 (3), 248-268. Do: Http: //Dx. Doi. Org/10.1016/J.Rser.2004.09.002

[9] Knothe G. (2007). Some Aspects of Biodiesel Oxidative Stability, Fuel Process Tchnol, 88, 669-77. 